\title{
On the development of Husserl's transcendental phenomenology of imagination and its use for interdisciplinary research ${ }^{1}$
}

\author{
JULIA JANSEN \\ Department of Philosophy, University College Cork, Ireland \\ (E-mail:j.jansen@ucc.ie)
}

\begin{abstract}
In this paper I trace Husserl's transformation of his notion of phantasy from its strong leanings towards empiricism into a transcendental phenomenology of imagination. Rejecting the view that this account is only more incompatible with contemporary neuroscientific research, I instead claim that the transcendental suspension of naturalistic (or scientific) pretensions precisely enables cooperation between the two distinct realms of phenomenology and science. In particular, a transcendental account of phantasy can disclose the specific accomplishments of imagination without prematurely deciding upon a particular scientific paradigm for its experimental investigation; a decision that is best left to the sciences themselves.
\end{abstract}

Key words: imagination, interdisciplinarity, phantasy, transcendental phenomenology

\section{Introduction}

Despite Husserl's well-known and often quoted announcement that fiction is "das Lebenselement der Phänomenologie" (Husserl 1980, p. 148), that is, the 'vital element' that makes up the very life of phenomenology, his account of phantasy has been repeatedly characterized as unsatisfactory. The most common objection is that Husserl, although he rejects the Humean understanding of imagination as 'faint copy' of sensation, nevertheless degrades phantasy to a poor imitation of perception. Phantasy is described by him as quasi-perception (cf. Drost 1990; Sallis 1992; Saraiva 1970, p. 251). Further, Husserl has been criticized for remaining indebted to empiricism by claiming that phantasies are constituted by a specific apprehension of sensory contents. Finally, while Husserl is often credited for ascribing methodological merit to phantasy in his notion of eidetic variation, this 'merit' is often itself perceived as one of the most questionable elements of the phenomenological method. Thus, in the light of these objections, Husserl indeed appears to be "yet one more in the tradition of writers whose words do not match his deeds in the affairs of the imagination" (Brann 1991, p. 122).

Yet, Husserl discusses phantasy not only in the manuscripts explicitly engaged in its description (published in Husserl 1980), but in almost all his philosophical works spanning from the Logical Investigations (1900/1901) to the posthumously published Experience and Judgment (1939). In this paper, I will first offer an explanation for the apparent tension between the critical systematic importance Husserl attributes to the notion of phantasy for 
phenomenology and shortcomings repeatedly pointed out by his critics. In short, this tension ensues from what I call the 'early account' of phantasy, which is based on the content-apprehension-schema. It assumes the occurrence of phantasmata (phantasmatic contents) turned into phantasies by a specific mode of apprehension - a conception of phantasy that, in my opinion, indeed justifies the charge of empiricism. In the second section of this paper, I want to draw attention to a less crude conception of phantasy that Husserl develops in his later writings, in which he claims that all acts are 'consciousness through and through' [Bewußtsein durch und durch] (Husserl 1980, text 8 [1909] p. 265). ${ }^{2}$ This latter view marks the crucial step towards a transcendental phenomenology of imagination, which I will expound in the third part of this paper. It finally refutes the supremacy of perception and overcomes the empiricist legacy in order to give way to a 'first philosophy of phantasy.'

What these three parts of my paper leave untouched, however, is the underlying value judgment that Husserl's turn away from an empiricist explanation and toward a transcendental clarification means indeed an improvement of his account. Especially in view of recent attempts to 'naturalize' phenomenology, this assumption cannot simply be taken for granted but clearly requires an argument for its defense. The growing affinity with cognitive science could be taken to suggest that phenomenology becomes more useful the more empiricist it becomes. In fact, the project of transcendental phenomenology might appear outdated and naïve. In the conclusion, I will therefore outline what I think a specifically transcendental phenomenological account has to offer for a fruitful cooperative investigation of imagination in phenomenology and cognitive science. ${ }^{3}$

\section{Empiricist vestiges: Husserl's early account of imagination}

The parallelism between perception and phantasy remains the leading systematic idea of Husserl's investigations of imagination throughout the years (cf. Husserl 1984, p. 679 f.; Husserl 1969, p. 128; Husserl 1959, p.115 and 119; Husserl 1973a, p. 21 f.) Perception is a presentation [Gegenwärtigung], "in which the object appears to us, so to speak, 'in person' [leibhaftig], as itself present." Phantasy, conversely, is a presentification [Vergegenwärtigung], "in which the object appears but does so not as present, rather as merely presentified [vergegenwärtigt]. It appears as if it was there but only as if ..." (Husserl 1980, text 1 [1904/05], p. 16). Despite this distinct difference, however, phantasy is like perception in all essential respects; it is as if-perception. On the basis of this parallelism Husserl enlarges the concept of experience [ $E r-$ fahrung], or intuition [Anschauung] so that it then includes perception as well as quasi-perception, i.e. phantasy. This turns the parallelism of perception and phantasy into a crucial moment in the development of the phenomenological 
method. This is because the enlargement of the concept of experience, allowed by the structural similarities between perception and phantasy, is a necessary condition for phenomenological analysis.

First, the parallelism of perception and phantasy can be regarded as the justification for using phantasy as an illustrative model for experience in general. Accordingly, whatever moments or relations are made evident in phantasy are also taken to be evident for perception, or for experience in general. Second, the intuition of essences in particular requires the parallelism between perception and phantasy. For, if there was a difference between the essence that we access by means of eidetic variation in phantasy and another essence that is issued by comparing actual perceptions, then it would obviously be very difficult for Husserl to defend his talk of essences at all. The notion of essence, after all, implies that it is possible to disregard any difference between its perceptual or phantasmal exemplifications. "The eidos," Husserl clearly states in Section 3 of Ideas I, "the pure essence, can exemplify itself intuitively (...) in what is given in perception (...), but just as well in what is given in mere phantasy" (Husserl 1950, p. 13; cf. Husserl 1984, pp. 634 f., 661). In short, what is a priori about the essence is precisely its independence from experience, and therewith its independence from any differences between phantasy and perception. However, this independence, in turn, depends on the essence being common to both kinds of its concrete exemplification so that they are, in this sense, essentially the same.

However, if there is a phenomenologically demonstrable parallelism between perception and phantasy, then phantasy and perception must show themselves to be parallel; it must be evident that they are (cf. Husserl 1984, p. 679 f.). ${ }^{4}$ However, Husserl's claims in the Logical Investigations about the "necessary parallelism" between perception and phantasy, whereby a possible phantasy "of the same essence corresponds to every perception," are at that point not supported by phenomenological evidence and are nothing more than unfounded assumptions.

In his early work, then, Husserl understands phantasy as a type of pictorial presentation [Bildlichkeitsvorstellung] that resembles pictureconsciousness [Bildbewusstsein] (Husserl 1980, text 1 [1904/05], p. 16). Picture-consciousness involves 1) the picture as physical object (the canvas which somebody painted on, or the paper which somebody printed on, etc.); 2) the picture-object (the figure that appears through a certain distribution of colors and shapes); and finally 3) the picture-subject (what is depicted by that figure) (Ibid., pp. $19 \mathrm{ff}$.). Accordingly, the mental image of phantasy (the figure appearing in front of 'my mind's eye') is analogous to the pictureobject (the figure appearing on the canvas). Both picture-object and mental image are 'truly nothing' (Ibid., p. 46). While the picture-subject appears in them, they themselves do not appear at all; we see the picture-subject through them. Thus, on this early account both phantasy and picture-consciousness 
are characterized by a 'double objectivity' [eine doppelte Gegenständlichkeit] (Husserl 1980, Beilage 1 [1898], p. 112). In both cases, thus the analogy, we apprehend something as representing something other than itself, as making something other than itself appear.

However, the analogy between phantasy and picture-consciousness turns out to be untenable. To begin with, the picture-object needs the physical picture as a carrier of its sensual content. There simply would be no shape, no figure without a canvas of which we have an actual sensation delivering a sensual content that we apprehend as a shape or a figure. However, phantasmatic contents, or phantasmata, cannot be said to be present to us in the same way. And even if they were, it would remained inexplicable how they could and why they would be apprehended precisely as something absent, as merely phantasized. Moreover, in opposition to Husserl's view in his early lectures on phantasy "When we phantasize, we intend some other thing than the appearing one, which can be felt to be distinct from it and which pictorially represents it" (Husserl 1980, text 1 [1904/05], p. 29) - it is not necessary that a phantasy presentation intends an object 'depicted' by the mental image. Thus, nothing in phantasy corresponds to the picture-subject in picture-consciousness. Finally, perception - which supposedly is parallel to phantasy - precisely does not imply such a double intentionality. That is what it means to say that the perceived appears 'in person.' Thus, if phantasy did show the same kind of double intentionality as picture-consciousness, it would in fact be essentially different from perception and not essentially like it.

\section{Transcendental transformations: Husserl's revised account of imagination}

During the time between the Logical Investigations and Ideas I Husserl's investigations of phantasy are first and foremost concerned with the status of phantasmata. In his early work he had understood phantasmata as present intuitive unities through which we intend phantasized objects. The decisive step that Husserl takes in his revisions of this early account is precisely the dismissal of an understanding of phantasmata as something present, as "a kind of thing [ein Sächelchen]" (Husserl 1950, p. 253).

We do not experience a phantasma as something present that presentifies something absent. The phantasized object itself appears in phantasy, just as the perceived object itself appears in perception. "One does not regard the image as an object constituted in its own right, which one grasps as such and takes as an image. Rather, through this peculiarly volatile something the intention is directed to the object" (Husserl 1980, Beilage X [probably 1905], p. 161; ibid. Beilage IX [probably 1905], p. 150; Husserl 1950, p. 90; Hua 1959, 112 f.; Husserl 1969, p. 183). 
Phantasmata, then, are presentified [vergegenwärtigte] sensations (Husserl 1980, text 1 [1904/05], p. 77). Phantasy consciousness is directly and thoroughly modified as presentifying consciousness [vergegenwärtigendes Bewußtsein]. The talk of phantasmata and, a fortiori, of the contentapprehension-schema is thus revealed as a (perhaps for some analyses helpful) construction. It becomes clear that Husserl's early notion of phantasy indeed "falls behind his own proper method and introduces into phenomenology remainders of empiricist positivism" (Saraiva 1970, p. 249). And in a text on phantasy from 1909 Husserl decides to reject his earlier explanatory model:

I had the schema 'apprehended content and apprehension' and that certainly made good sense. But we do not have, first in the case of perception, in the concrete lived experience a color as the content of apprehension and then the character of the apprehension, which makes for the appearance. And likewise we do not, in the case of phantasy, have again a color as content and then a modified apprehension, which makes for the phantasy appearance. Rather: 'Consciousness' consists of consciousness through and through, and even sensations as well as phantasmata are 'consciousness' (Husserl 1980, text 8 [1909], p. 265).

In other words, there is nothing in consciousness that is not already intentional; there are no mere contents that can be viewed in separation from their apprehensions. Phantasies do not consist of present contents presentifying a non-present object. Our phantasies are as immediate as our perceptions.

What remained paradoxical according to the early account, namely that something absent (the phantasized object) should be seen in something present (the phantasma), is now resolved into the correlation of noesis and noema. Noetically, phantasies are in fact present in so far as they are presently lived through in inner consciousness. Noematically, however, what is presentified is taken as absent. This way Husserl can analyze phantasy into reproduction [Reproduktion] on the noetic side and presentification [Vergegenwärtigung] on the noematic side. Noetically speaking, a phantasy reproduces an originary lived experience. Noematically speaking, it presentifies an intended object.

To sum up, both intentional acts - phatasy and perception - directly constitute an object and let it appear; their objects display, as Husserl discovers in his investigations on time-consciousness, the same temporal adumbrations (Husserl 1969, p. 41); the presentified noema [das Noema der Vergegenwärtigung] is 'consciousness of' in essentially the same way as the presentiated noema [das Noema der Gegenwärtigung]. Noematically, then, phantasy and perception are indeed essentially alike. Noetically, however, phantasy and perception are essentially different. The phantasy noesis is not given as original consciousness but as reproduction. As such a reproduction, it always implies an original perception (cf. Bernet 2002, p. 340). 


\section{Phantastic possibilities: Husserl's transcendental phenomenology of imagination}

The merit of Husserl's revised account of phantasy is that it puts us in the position to structurally describe the noetic-noematic correlations of phantasy consciousness in its givenness while we may disregard the 'natural' or empiricist question of the presence or absence of sensuous contents. According to Husserl, the suspension of this question releases phenomenology from the charge of subjectivist empiricism and constitutes phenomenology as a truly transcendental enterprise.

\footnotetext{
In its purely eidetic attitude, which 'brackets' all transcendence, phenomenology necessarily reaches on its own ground of pure consciousness this entire complex of transcendental problems in the specific [phenomenological] sense and therefore deserves the name transcendental phenomenology. On its own ground it must arrive not at regarding the lived experiences as arbitrary dead entities, like 'complexes of contents' (...) but at seizing the essentially genuine problem which they pose as intentional experiences and do so purely by means of their eidetic essence as 'consciousness of' (Husserl 1950, p. 198).
}

Most importantly, with the help of the phenomenological reduction we can finally discover the "peculiar specialties phantasy accomplishes" (Husserl 1959, p. 134). For phantasy can in fact provide us with something that actual perception is unable to offer: it constitutes possibilities. Although phantasy with its "voluntary refrain from any position" belongs to "the realm of purposelessness, of play" (Husserl 1980, text 20 [1921/24], p. 577; Husserl 2000, pp. 10-14) and thus seems incapable of constitutive accomplishment (Husserl 1980 , text 19 [probably 1922/23], p. 558), in its play it frees us from the limits of our actual perceptions. It is "a modification of perception that is implied as a possible and not as an actual act" (Bernet 2002, p. 339). What can be seen as an as if-appearance of an actual object is in fact also an actual appearance of a possible object (Husserl 1980, text 18 [1918], p. 507; Beilage LVI [probably 1918], p. 529; text 19 [probably 1922/23], pp. 547 f.; Husserl 1973, pp. 66, 94; Husserl 1986, p. 170). In phantasy, I can both presentiate a possibility or presentify an actuality (Husserl 1959, pp. 116-119). The possibility that is revealed in phantasy is not theoretical or conceptual; it is - very much in the Kantian sense - a possible object of experience.

This insight is central to a phenomenological justification of a priori judgments and eidetic laws. If phantasy accomplished nothing but the neutralization of positing acts, if it only produced the mere 'quasi' of acts, it would be indeed problematic to base any essential knowledge on it at all (Kuspit 1968, pp. 16-33). If, however, phantasy can be said to posit possibilities, then phantasy allows us to phenomenologically demonstrate a priori judgments. The object phantasized, for example, a triangle, can then be taken as 'any possible 
triangle' or the possibility of triangles as such. In this way, any judgment about the phantasized triangle becomes an a priori judgment about triangles in general. Such possibilities are, in the phenomenological sense, scientifically relevant - which is admittedly more obvious in the case of geometrical than in the case of ordinary objects ${ }^{5}$ - because they do not merely refer to "what can possibly be thought" [reines Denkbarsein]" (Husserl 1973a, p. 450 f.) but to what can be intuited. They can be made evident in phenomenological analysis and thereby yield, in Husserlian terms, synthetic judgments $a$ priori.

This precisely refutes the empiricist positivistic convictions of the supremacy of perception and the derivative character of phantasy. For it means that phantasy and perception are indeed parallel acts of consciousness, each act with its own evidential force. Whereas perception provides us with evidence in the realm of transcendent experience of actual objects, phantasy provides us with possibilities and likewise does so with evidence. Thus, this parallelism does not imply, as is so often claimed, that Husserl simply moulds his notion of phantasy on his notion of perception and that therefore perception serves as a model for phantasy. The opposite holds true: by being able to phenomenologically demonstrate this parallelism in his later analyses of phantasy, Husserl is in the position to justify what other sciences and other philosophical schools have taken for granted, namely that we can take what we see in phantasy as possible experience, in other words, that we can use phantasy as an illustrative model for experience in general.

Hence, what could only be assumed on the basis of Husserl's early account of phantasy and what is assumed by other philosophies and eidetic sciences is now evident. "From every concrete actuality and every single feature that is actually experienced and can be experienced in it the way is open to a realm of ideal or pure possibility and, thereby, to a priori thought" (Husserl 1973a, p. 428). Fiction, then, is indeed the source, "from which the cognition of "eternal truths' takes its nourishment" (Husserl 1950, p. 148). It enables phenomenology as "an a priori science, which remains in the realm of pure possibility (i.e. pure imaginability [Vorstellbarkeit, Phantasierbarkeit]). Instead of making judgments about transcendent existing entities [Seinswirklichkeiten], it makes judgments about a priori possibilities and thereby draws out rules a priori for reality" (Husserl 1973, Sections 12, 29).

Thus, what becomes evident in Husserl's phenomenological account of phantasy is that it fulfills a transcendental function, again very much in the Kantian sense: it deals with "our way of cognizing objects in general in so far as that way of cognizing is to be possible a priori" (Kant 1996, B25/A12). Husserl thus clarifies phantasy as one of the crucial moments of his own method (Husserl 1950, p. 121) and as one of the assumptions on which the experimental sciences are based. A phenomenology of phantasy therefore truly is first philosophy. 


\section{Conclusion and prospect: Of what use is transcendental phenomenology?}

In the investigation above I showed that Husserl overcame the empiricist legacy in his revised notion of phantasy and thus developed a truly transcendental account. Further, I argued that the phenomenon of phantasy had a constitutive impact on Husserl's approach as a whole. The particular structure of phantasy presentations - specifically the circumstance that they present something that is itself absent - forced Husserl to rethink his content-apprehension-schema and to thus shed his empiricist vestiges. This argument, however, implies that Husserl's move to a transcendental account of phantasy is indeed an 'improvement.' After all, this assumption is hardly self-evident. On the contrary, the entire project of transcendental phenomenology as such has been rigorously critiqued. Varela and others have proposed that a naturalized phenomenology should take the place of the transcendental endeavor. Such a naturalized phenomenology would unify "the investigation of phenomenological data with the multilevel explanation of what is to be considered, in a naturalist perspective, as an essentially physical reality" (Petitot et al. 1999, p. 75).

On the contrary, a transcendental phenomenology is supposedly indebted to an outdated notion of science that used to justify a certain kind of skepticism towards any collaboration between phenomenology and the sciences and therefore advanced their strict separation. Above all, transcendental phenomenology is said to have announced the foundational status of phenomenology without being able to see that, in Alan Murray's words, "there is no realm beyond the level of practice and that the truth of knowledge must necessarily be coextensive with the methods and procedures by which it is produced" (Murray 2002, p. 31). There are "no concepts which underlie any and all empirical investigations" and questions "concerning methodology can never be settled in advance of actual investigations, because any discussion of method is necessarily going to entail certain presuppositions about the nature of the objects to which a given method relates" (Ibid. 33). Thus, according to this view, transcendental phenomenologists suffer from a "delusion of omnipotence, the belief that they possess some special set of analytical tools which allows them to 'complete' or 'run ahead of the science" (Ibid. 43). As soon as phenomenologists will be healed from this delusion, however, they will come to realize that there "is no unique or transcendental perspective from which the philosopher can survey and pronounce upon epistemological matters, there is only the messy and imperfect business of research and theoretical innovation (Ibid. 39).

In the light of these objections, I will conclude with a few words on what I believe are the merits of a transcendental account. I readily admit that I have a quite optimistic view on a possible common future for transcendental phenomenology and the sciences, in particular cognitive sciences. Consequently, 
I do not see the need for an abolishment of transcendental phenomenology. On the contrary, it is my contention that rather than being in opposition to the project of naturalized phenomenology, transcendental accounts can make a useful contribution to an interdisciplinary debate on matters of consciousness.

There are two common views on what transcendental phenomenology supposedly entails that I would like to reject from the beginning. First, transcendental phenomenology does not have to assume and then investigate a 'transcendental consciousness' that stands over and above empirical consciousness and is ontologically prior to the human brain. Second, transcendental phenomenology does not have to assume any conceptual, explanatory, or analytical priority, or even superiority over the sciences. In short, transcendental phenomenology - regardless of positions to the contrary possibly maintained by particular 'transcendental phenomenologists' neither necessarily implies that what it investigates is opposed to and superior to anything empirical, nor does it necessarily imply that the method it employs is opposed to and superior to any other scientific method.

But what makes a transcendental account transcendental then? A transcendental phenomenology of consciousness suspends (ideally) all existing theories of mind and scientific explanations of consciousness. It describes the acts in which consciousness constitutes certain objects (be they perceptual, imaginary, ideal etc.) and how they are experienced without speculating on their causal explanations. These descriptions will display certain moments that can be named by phenomenological terms ('noema,' 'adumbration,' 'presentification,' etc.) and thus reveal a phenomenological structure that belongs to the investigated act or experience. This method is transcendental because (a) it regards the ways in which consciousness constitutes experiences, objects, an environment, and ultimately what we call 'the world' (note here, that by 'consciousness' is not necessarily meant egoistic; in fact, it could involve intersubjective moments and environmental influences ${ }^{6}$ ) and (b) it suspends (ideally) all natural presuppositions, i.e., theories of mind, scientific hypotheses, etc. With respect to (a), this means that in his account of phantasy Husserl does not regard phantasy presentations as ready-made 'mental images' but as accomplishments of consciousness, that is, presentifications. The problem that I drew attention to above, however, arose with (b), that is, the fact that he did leave certain natural presuppositions in play initially. Among these was the presupposition of 'contents' that lay in consciousness to be 'apprehended' - thus my claim that it was only when Husserl finally rejected the 'content-apprehension-schema' that his account became transcendental.

What is gained by the final transcendental account of phantasy, then, is a description of the experience of phantasy and of structures manifest in its constitution. The description transcendental phenomenology is able to provide does not anticipate or even pre-determine a particular conceptual paradigm 
that a scientific explanation would have to follow. Obviously, most philosophers are - like me - just not trained to make any scientific claims. Thus, it is very important - and can be considered a matter of philosophical ethos that we keep within the framework of our discipline. Therefore, my claim that Husserl had to abandon the empiricist or positivist remains in his account does not imply any objections against attempts to explain phantasy empirically. Rather, it means that from the start Husserl should not have illegitimately introduced notions and terms from a domain, namely the domain of scientific explanation, which his method is not equipped to deal with.

As phenomenologists, philosophers can provide the sciences with webs of structural descriptions that can be used as points of reference for scientific explanations. It is important to keep in mind here that these descriptive webs cannot be reduced to any scientific explanation and vice versa. Husserl's 'transcendentalism' strictly distinguishes between the region of nature and the 'transcendental' region of consciousness as two irreducibly distinct essences. "According to Husserl, the 'transcendental' region of consciousness does not reduce to the "natural' region of physical causation" (Smith 1999, p. 106). As David Woodruff Smith put it, "Consciousness and its intentionality are part of nature. But their essence is not exhausted by physical composition or causal role or neural function or computation (classical or connectionist) ..." (Ibid., p. 83). Thus, to reduce the domain of consciousness to a scientific explanation means to commit, not a category mistake, but, if you will, an 'essence mistake.'

But even then, the essential distinction between transcendental accounts of consciousness and scientific accounts of the human brain could be taken to suggest that transcendental phenomenology is simply irreconcilable with the sciences and therefore unsuitable for any project that tries to promote cooperation of the sciences and philosophy. However, we do not have to draw that conclusion at all. Transcendental phenomenology and neuroscience, in my view, can very well enter a dialogue of ongoing inter-correction where interpretations of scientific facts have to be compatible with phenomenological descriptions of human experience, while phenomenological descriptions should not contradict, nor ignore scientific findings. ${ }^{7}$ This intercorrection would be a truly inter-disciplinary process in which it is important that each discipline is aware of its own method, its potential, and its limitations.

There will be some for whom this account deflates the notion of the transcendental. In my view, on the contrary, one of the most promising elements of Husserlian phenomenology is that it allows for a reading of the transcendental standpoint that is clearly distinguished from the naturalistic (or empirical) one without, however, being opposed to it. Husserl's transformation of the concept of transcendentality brings with it a new promise for a long-sought cooperation between philosophy and the sciences. 


\section{Notes}

1. You will find a more extensive version of the first sections of this paper in Rudolf Bernet, Donn Welton, Gina Zavota (eds), in press. Husserl: Critical Assessments (5 vol.). London: Routledge.

2. Rudolf Bernet already pointed to the transformation of Husserl's conception of phantasy in Bernet (2002) pp. 336-339.

3. I would like to thank the participants of the 2002 Colloquium of the International Association for Phenomenology and the Cognitive Sciences on imagination for a stimulating discussion of this problem. I am especially grateful for comments and suggestions I received from Jonathan Cole, Shaun Gallagher, James Mensch, and Alan Murray.

4. For a similar view see Volonté (1997, p. 107).

5. One could say that this is the crux of the legitimation of the phenomenological method. In the light of the Kantian notion of figurative synthesis, the question Husserl has to answer is whether we can have pure intuitions (eide) that go beyond the Kantian forms of intuition. But that's a topic for a different paper.

6. After all, "the proper subject of perception is not the brain, but rather the whole embodied animal interacting with its environment" (Thompson et al. 1999, p. 185 f.).

7. Jean-Luc Petit (2003) also emphasizes the compatibility of transcendental phenomenology and neuroscientific research.

\section{References}

Bernet, R. 2002. Unconscious consciousness in Husserl and Freud. Phenomenology and the Cognitive Sciences 1: 327-351.

Brann, E. 1991. The World of Imagination. Boston: Rowman and Littlefield.

Drost, M. 1990. The primacy of perception in Husserl's theory of imagining. Philosophy and Phenomenological Research 1(3): 569-582.

Husserl, E. 2000. Aktive Synthesen: Aus der Vorlesung 'Transzendentale Logik' (1920/21) (Husserliana XXXI). Den Haag: Kluwer.

Husserl, E. 1986. Aufsätze und Vorträge (1911-1921) (Husserliana XXV). Den Haag: M. Nijhoff.

Husserl, E. 1984. Logische Untersuchungen. Zweiter Teil. Untersuchungen zur Phänomenologie und Theorie der Erkenntnis (Husserliana XIX/2). Den Haag: M. Nijhoff.

Husserl, E. 1980. Phantasie, Bildbewusstsein, Erinnerung (Husserliana XXIII). Den Haag: M. Nijhoff.

Husserl, E. 1973. Cartesianische Meditationen und Pariser Vorträge (Husserliana I). Den Haag: M. Nijhoff.

Husserl, E. 1973a. Experience and Judgment, Translated by J. Churchill and K. Ameriks. Evanston: Northwestern University Press.

Husserl, E. 1969. Zur Phänomenologie des inneren Zeitbewusstseins (1893-1917) (Husserliana X). Den Haag: M. Nijhoff.

Husserl, E. 1959. Erste Philosophie (1923/4). Zweiter Teil: Theorie der phänomenologischen Reduktion (Husserliana VIII). Den Haag: M. Nijhoff.

Husserl, E. 1950. Ideen zu einer reinen Phänomenologie und phänomenologischen Philosophie. Erstes Buch: Allgemeine Einführung in die reine Phänomenologie (Husserliana III). Den Haag: M. Nijhoff.

Kant, I. 1996. Critique of Pure Reason. Translated by Werner Pluhar. Indianapolis/Cambridge: Hackett. 
Kuspit, D. B. 1968. Fiction and phenomenology. Philosophy and Phenomenological Research 29: $16-33$.

Murray, A. 2002. Philosophy and the 'Anteriority Complex.' Phenomenology and the Cognitive Sciences 1: 27-47.

Petit, J.-L. 2003. On the relation between recent neurobiological data on perception (and action) and the Husserlian theory of constitution. Phenomenology and the Cognitive Sciences 2: 281-298.

Petitot, J., Varela, F., Pachoud, B. and Roy, J.-M. (eds). 1999. Naturalizing Phenomenology. Stanford: Stanford University Press.

Sallis, J. 1992. Spacing imagination. Husserl and the phenomenology of imagination. In: P. Van Tongeren et al. (eds), Eros and Eris (pp. 201-215). Dordrecht: Kluwer.

Saraiva, M. 1970. L'imagination selon Husserl. Den Haag: M. Nijhoff.

Smith, D. W. 1999. Intentionality naturalized? In: J. Petitot et al. (eds), Naturalizing Phenomenology (pp. 83-110). Stanford: Stanford University Press.

Thompson, E., Noë, A. and Pessoa, L. 1999. Perceptual completion: A case study in phenomenology and cognitive science. In: J. Petitot et al. (eds), Naturalizing Phenomenology (pp. 161-95). Stanford: Stanford University Press.

Volonté, P. 1997. Husserls Phänomenologie der Imagination. Freiburg: Alber. 